\title{
Non-pharmaceutical intervention and pain management situation for neonatal analgesia
}

Review

\author{
Zi Zeng ${ }^{a, *}$, Yan-Xia Duana, Guo-Min Song ${ }^{\mathrm{b}}$ \\ aHenan Vocational College of Nursing, Anyang, Henan 455000, China \\ ${ }^{b}$ Department of Nursing, Tianjin Hospital, Tianjin 300211, China
}

Received: 28 April 2020; Accepted: 11 June 2020; Published: 20 December 2020

\begin{abstract}
Neonatal pain management is an important issue which should have great attention. More and more researches have proved that neonates can feel pain when undergoes painful procedures such as vaccination, heel stick, and so on, and it will result in shortterm and long-term outcomes. So it is very important to manage neonatal pain. This article summarized some non-pharmaceutica interventions, including sucrose or glucose, non-nutritional sucking (NNS), breastfeeding, facilitated tucking (FT), kangaroo mother care (KMC), swaddling, heel warming, sensorial saturation (SS), and music therapy, which showed obvious effects for neonatal pain. In addition, this article summarized the progress of neonatal pain intervention in various countries and showed that many countries have not paid enough attention to this problem, while some countries have carried out promotion programs for neonatal pain management which give some clinical enlightenment to our country that we need to pay more attention to this problem.
\end{abstract}

Keywords: neonatal pain • pain management • non-pharmaceutical intervention

(c) Shanxi Medical Periodical Press.

\section{Introduction}

Pain is regarded as unpleasant feelings and emotional experiences associated with existing or potential tissue damage. ${ }^{1}$ Studies have shown that the experiences of pain in newborns are similar to that in adults, with behavioral, cardiovascular, respiratory manifestations. ${ }^{2}$ Uncontrolled pain may lead to short (physiological and behavioral) and long-term results (decreased pain sensitivity, blunted cortisol responses, and high incidences of neuropsychiatric diseases). ${ }^{3}$ Memories of pain may be recorded biologically and alter brain development and subsequent behavior. ${ }^{4-6}$ Repeated pain process may influence brain development and neurodevelopment, especially for very preterm infants. So it's essential to help those infants for relieving their pain when undergoing painful procedures in communities or hospitals. ${ }^{7}$

Painful procedures such as heel sticks, arteriovenous punctures and intubations, invasive procedures such as endotracheal intubation and sputum aspiration can cause pain reactions. The neonates suffered from many painful procedures especially in neonatal intensive care units (NICUs). The interventions for painful protocols include pharmaceutical and non-pharmaceutical methods. Pharmaceutical treatments for neonatal pain has its limitations, and the use of non-pharmaceutical interventions can reduce the adverse drug reactions of the newborns to a certain extent.

How to cite this article: Zeng Z, Duan YX, Song GM. Non-pharmaceutical intervention and pain management situation for neonatal analgesia. Front Nurs. 2020;4:299-306. 
The aim of this study is to summarize the nonpharmaceutical methods for neonatal pain and current situations of pain management in various countries, which may give some guidelines for the implementation of normative neonatal pain management in our country.

\section{Pain management: Non-pharmaceutical interventions for neonatal pain}

Non-pharmaceutical measures are useful interventions which can reduce neonatal pain in a different way. The measures introduced in this article include sucrose or glucose, non-nutritional sucking, breastfeeding, facilitated tucking, kangaroo mother care, swaddling, heel warming, sensorial saturation, and music therapy, and they were proven effective for neonatal analgesia (Table 1).
The use of sucrose or glucose was proven to be effective for neonatal analgesic. ${ }^{8,9}$ Repeated use of sucrose is effective for term infants. Repeated uses of sucrose for preterm infants, and for the preterm infants $<31$ weeks receiving $>10$ doses of sucrose result in worse neurologic development. ${ }^{8}$ The research showed that $1 \mathrm{ml}$ of $25 \%$ or $50 \%$ glucose solutions had more satisfactory effects for those infants. ${ }^{9}$ The sucrose and radiant warmth group was proven more effective than sucrose group only for neonatal pain for the stabilization of cry, grimace, heart rate variability and heart rate. ${ }^{10}$

NNS is the use of an oral stimulant such as pacifiers without providing nutrition. The research showed that NNS is an effective method for preterm infants with stress-related behavior, abnormal heart rates, and oxygen saturation. ${ }^{11}$ Further, pacifiers have been proven more effective than sucrose and glucose in a randomized controlled trial. ${ }^{12}$ Oral inhalation of $24 \%$

\begin{tabular}{|c|c|c|}
\hline Methods & Major effects & Use in painful procedures \\
\hline $\begin{array}{l}\text { Sweet oral solutions } \\
\text { (sucrose or glucose) }\end{array}$ & $\begin{array}{l}\text { - Reduce behavioral pain response and composite } \\
\text { pain scores. } \\
\text { - } \quad \text { Decrease duration of cry. } \\
\text { - Stabilize changes of } \mathrm{HR}, \mathrm{SpO}_{2} \text {. }\end{array}$ & $\begin{array}{l}\text { - } \quad \text { Full term neonates } \\
\text { - } \quad \text { Preterm neonates } \\
\text { - } \text { Sucrose: small volumes of } 24 \%(0.1-0.3 \mathrm{ml} \text { for } \\
\text { - } \quad \text { Greterm neonates and } 1-2 \mathrm{ml} \text { for term neonates) } \\
\text { - } \quad \text { Concerns: potential neurological adverse effects } \\
\quad \text { for repeated use of sucrose in preterm infants } \\
\text { - Grade of recommendation: strong }\end{array}$ \\
\hline NNS & $\begin{array}{l}\text { - Lower pain scores (PIPP) } \\
\text { - Lower frequency of stress-related behaviors, } \\
\text { abnormal rates, oxygen saturation. }\end{array}$ & $\begin{array}{l}\text { - } \text { Preterm neonates } \\
\text { - } \text { At least performing } 3 \text { min before painful procedure } \\
\text { - } \text { Grade of recommendation: strong }\end{array}$ \\
\hline Breastfeeding & $\begin{array}{l}\text { - Reduce pain scores } \\
\text { - } \quad \text { Lower increase in heart rate } \\
\text { - Reduce cry time }\end{array}$ & $\begin{array}{l}\text { - } \text { Term infants } \\
\text { - } \text { Starting } 2 \text { min before and continuing the procedure } \\
\text { Grade of recommendation: strong }\end{array}$ \\
\hline FT & - Reduce pain perceptions & $\begin{array}{l}\text { - Term infants } \\
\text { - Performing during the procedure, such as received } \\
\text { vaccination, and safe in mechanically ventilated neonates } \\
\text { - Grade of recommendation: strong }\end{array}$ \\
\hline KMC & $\begin{array}{l}\text { - } \quad \text { PIPP } \\
\text { - } \text { Shorter time to recovery } \\
\text { - } \quad \text { Reduce cry time }\end{array}$ & $\begin{array}{l}\text { - Useful for very preterm neonates preterm neonates } \\
\text { - Grade of recommendation: strong }\end{array}$ \\
\hline Swaddling & $\begin{array}{l}\text { - Stabilization for heart rates, oxygen saturation } \\
\text { - PIPP }\end{array}$ & $\begin{array}{l}\text { - Preterm infants } \\
\text { - Grade of recommendation: strong }\end{array}$ \\
\hline Heel warming & $\begin{array}{l}\text { - } \text { Reduce pain response } \\
\text { - Improve pain recovery }\end{array}$ & $\begin{array}{l}\text { - Preterm infants } \\
\text { - Usually use before a heel stick } \\
\text { - Grade of recommendation: strong }\end{array}$ \\
\hline SS & - Reduce pain scores (ABC) scale) & $\begin{array}{l}\text { - } \text { Term neonates } \\
\text { - Grade of recommendation: strong }\end{array}$ \\
\hline Music therapy & $\begin{array}{l}\text { - Stabilize HR, SaO2, pain } \\
\text { - Improve physiological and behavioral parameters }\end{array}$ & $\begin{array}{l}\text { - } \text { Preterm neonates } \\
\text { - } \quad \text { Play familiar music of fetal period, light music } \\
\text { - } \text { or their mother's voice } \\
\text { - Grade of recommendation: weak }\end{array}$ \\
\hline
\end{tabular}

Note: NNS: non-nutritional sucking; FT: facilitated tucking; KMC: Kangaroo mother care; SS: sensorial saturation.

Table 1. Non-pharmaceutical interventions for neonatal pain. 
sucrose with NNS intervention performed before and during a painful procedure was associated with more effectiveness in neonates' pain relief based on the Neonatal Infant Pain Scale (NIPS) scores and painassociated variations such as $\mathrm{HR}$ and $\mathrm{SpO}_{2}$. It's also worth noting that complete analgesia for term infants might hamper their pain irritability. ${ }^{13}$ Moreover, the effect of NNS is limited according to one prior study because the efficacy ceases once the pacifier is removed from the infant, and may result in a greater degree of unease. So the effect of NNS may be limited and transient. ${ }^{14}$

Breastfeeding is an useful analgesic method for those neonates suffering due to venepuncture and can reduce pain degree during minor invasive procedures. ${ }^{15}$ Furthermore, glucose plus pacifier group have similar effects when compared with breastfeeding group. ${ }^{15}$ Breastfeeding was proven more effective in stabilizing heart rate, controlling pain degree than glucose, pacifier, and holding by mother groups. ${ }^{16}$ Breastfeeding was proven more effective using NIPS questionnaire than oral $25 \%$ dextrose, kangaroo mother care method (KMCM), and EMLA cream teams for term infants. ${ }^{17}$

FT is a special way of holding baby in a fixed position and even safe to use in mechanically ventilated neonates. ${ }^{18}$ FT group demonstrated lower pain scores for neonates who received hepatitis $B(\mathrm{HBV})$ vaccinations than classical holding position group. ${ }^{19}$

$\mathrm{KMC}$ is a method for infants holding by mothers with uttermost skin-to-skin contact at an angle of about $60^{\circ} .{ }^{20}$ It has been proven that very preterm neonates showed obvious effects. ${ }^{21}$ Lesser crying time observed in preterm infants with KMC when performing heel stick. ${ }^{22}$

Swaddling refers to restriction of the neonates' movement using a blanket or other available devise. ${ }^{23}$ Swaddling showed similar effect with $\mathrm{KMC}$ for relieving preterm infants' pain. ${ }^{24}$ While some studies may show the negative results, one study indicated that swaddling has no apparent effect for the neonates who are younger than 31 weeks gestational age. ${ }^{25}$

Heel warming is often used before a heel stick. A recent study showed that heel warming had an obvious effect for oxygen saturation. ${ }^{26}$ The possible mechanism was measures before heel stick can promote local blood circulation, thereby reducing the pain caused by local compression during blood collection.

SS is an effective procedure that includes massage, scent, voice, sight, and touch interventions. The specific steps include attracting the neonate's attention and speaking and massaging to the baby, and then feeding the baby with $1 \mathrm{ml}$ of $33 \%$ glucose solution, and allowing the baby to suck a pacifier before and during the painful period. ${ }^{27}$ It is easy to learn, and can be performed by nurses or the neonates' mothers, with similar effects.

Music therapy showed a positive effect for pain relief, $\mathrm{HR}, \mathrm{SaO}_{2}$ stabilization, and physiological and behavioral signs improvement. ${ }^{28}$ And for the style of music, familiar music listened in fetal period were preferred. ${ }^{29}$ The effect of mother's voice was good for relieving pain for neonates who suffered arterial blood sampling. ${ }^{30}$ So mothers' voice may be a good choice for music therapy, which can be recorded first, and played when their babies are suffering due to painful procedures.

Also, combined methods may work better. Effect of music with NNS, FT, and holding group showed more effective in PIPP scores, heart rate, oxygen saturation and abnormal heart rate for neonatal pain. ${ }^{31}$ Combined music and touch therapy proved more effective than control group for late preterm infants on painful scores. ${ }^{32}$ Using a combination of them, such as sucrose and radiant warmth group, sucrose with NNS group, music, NNS and FT group can obtain better effectiveness. ${ }^{10,13,31,33}$ Moreover, SS is a combination of sensory stimuli, hence is a good method and may be more useful than single stimulus.

Furthermore, the use of those methods mentioned above such as the use of NNS, glucose, sucrose also showed a good effect in China. ${ }^{34-36}$ Among the interventions, NNS, FT, swaddling, KMC, SS, sucrose or glucose, breastfeeding were classified for strong recommendation, while music therapy classified for weak recommendation, ${ }^{37}$ and so music therapy need further research to prove its effect. Evidence from a research showed that different non-pharmaceutical measures can be performed for preterms, neonates, and older infants to relieve pain under procedures. And the most recommended methods were NNS, swaddling, FT, and holding. ${ }^{38}$

\section{The practices of neonatal analgesia in different countries}

It is well known that newborns can feel pain, while there is a gap between theory and practice. Many clinical workers and parents of newborns do not have exact knowledge of neonatal pain assessment and intervention. So, we summarized the current situation of cognition and intervention on neonatal pain in various countries, which enables us to understand in a better way.

Some Chinese researches showed that the nurses who were investigated know little about pain assessment and intervention methods for neonates. ${ }^{39,40}$ One 
study from China showed that the effect of the intervention group for neonatal pain management, which involved the neonates' parents, was better than the control group. ${ }^{41}$ Training of knowledge and attitude of neonatal pain management for the nurses working in NICUs had a positive effect. ${ }^{42,43}$

One study from Brazil concluded that only $26 \%$ physiotherapists acknowledge that neonates experience pain like adults, and if an intervention is painful for adults, it should be considered the same for neonates. Further, only $37 \%$ of investigated units had pain assessment protocols. Among the painful procedures, venepuncture and blood collection were considered the most common procedures that cause pain. ${ }^{44}$ Neonates received few pain relief measures during hospitalization in NICUs. ${ }^{45}$ An investigation in Brazil showed that in those preterm infants investigated, daily average painful interventions were 5.37 , while the neonates with invasive ventilation were most exposed to painful procedures $(71.2 \%)$, but only $44.9 \%$ received pain relief interventions. ${ }^{46}$

Research on Iran showed that the nurses had performed poorly in evaluation and relief of neonatal pain, even though they had positive attitude for this. ${ }^{47}$ One study conducted in India which showed that neonates in NICUs suffered from pain from many painful procedures, while almost $2 / 3$ of the times, but no pain relief methods were used which revealed the poor implementation of pain management for neonates in NICUs. ${ }^{48}$ In Japan, a pain management improvement program was implemented in seven Japanese level 3 NICUs, which used for the neonatal pain management quality improvement over 12 months. All included NICUs used new pain assessment tools, interventions, and recorded the information in electronic way using computer, and received good effectiveness. This may give us some implications for our pain management practice. $^{49}$

Most of the time, clinical workers may neglect neonates' parents, who worry deeply about their babies especially when undergoing painful procedures and so one program in Canada named Baby-Friendly Initiative was implemented. They made a five-minute videotranslated in Chinese language-played on websites, in which it is shown that babies undergoing blood collections while they were on breastfeeding, held skinto-skin and feeding sucrose by mouth. It showed how parents can help their babies with these intervention strategies. And one mother who performing this considered these strategies was useful and enforceable. She believe that successful implementation of these strategies need good cooperation between parents and clinical workers. ${ }^{50}$

\section{Discussion}

Neonatal pain may influence their brain development and neurodevelopment. ${ }^{7}$ So, pediatric nurses should pay attention to this point and cope with this problem positively. This article summarized many nonpharmaceutical neonatal analgesic methods including sucrose or glucose, non-nutritional sucking, breastfeeding, facilitated tucking, kangaroo mother care, swaddling, heel warming, sensorial saturation, and music therapy and found that inadequate pain management and insufficient cognition in neonatal pain worldwide.

\subsection{Implementations for practice}

Although more and more researches pay attention to the problem of neonatal pain management, many clinical workers fail to pay attention to this problem in practice. Especially in Chinese hospitals, we should promote the practice and training for the nurses in neonatal pain management and it is not only to improve their cognitive level, but also their practice ability. Now, we have carried out some neonatal pain management in Chinese hospitals, while that is not enough. Therefore, we should promote neonatal pain management in clinical work and implement some feasible promotion projects in the future. Also, we should suggest hospital managers to promote pain management training for neonates, teach some feasible analgesia methods of neonates to nurses and even parents, and drive on hospitals to promote pain management for neonates, especially for neonates in NICUs. Further, clinical medical staffs should learn appropriate methods and intervention measures for neonatal pain assessment, find suitable methods for different newborns and implement for them, and make appropriate education to the parents of newborns. Parents of newborn babies, especially mothers, should also be involved in pain management of their newborn babies. For example, breastfeeding is a useful analgesic method that must be implemented by their mothers.

\subsection{Implications for research}

Even though the analgesic methods mentioned above are very useful, it needs further corroboration. It is observed that (1) the efficacy of NNS is transient and limited, ${ }^{14}(2)$ the effect of swaddling has no apparent effect on the neonates younger than 31 weeks gestational age, ${ }^{25}$ and (3) repeated use of sucrose, i.e., $>10$ doses of sucrose for preterm infants $<31$ weeks gestational age had worse neurologic development. ${ }^{8}$ These limitations need more researches to prove it. 
Now there are many mature scales for evaluating neonatal pain and methods for alleviating pain. So, we should develop localized applications of scales and clinical practice of analgesia methods so that these scales can be applicable for Chinese neonates, which will help to promote the progress of neonatal analgesia in China.

\section{Conclusions}

The measures introduced in this article such as sucrose or glucose, non-nutritional sucking, breastfeeding, facilitated tucking, kangaroo mother care, swaddling, heel warming, sensorial saturation, and music therapy were proved effective for neonatal analgesia. Among these interventions, NNS, FT, swaddling, $\mathrm{KMC}$, SS, sucrose or glucose, breastfeeding were graded for strong recommendation, and music therapy was graded for weak recommendation. A huge gap still

\section{References}

1. Stevens B, McGrath P, Gibbins S, et al. Procedural pain in newborns at risk for neurology impairment. Pain. 2003;105:27-35.

2. Puchalski M, Hummel P. The reality of neonatal pain. Adv Neonatal Care. 2002;2:233-244.

3. Porter FL, Wolf CM, Miller JP. Procedural pain in newborn infants: the influence of intensity and development. Pediatrics. 1999;104:e13.

4. Anand KJ, Scalzo FM. Can adverse neonatal experiences alter brain development and subsequent behaviour? Biol Neonate. 2000;77:69-82.

5. Victoria NC, Murphy AZ. The long-term impact of early life pain on adult responses to anxiety and stress: historical perspectives and empirical evidence. Exp Neurol. 2016;275(Pt 2):261-273.

6. Vinall J, Miller SP, Bjornson $\mathrm{BH}$, et al. Invasive procedures in preterm children: Brain and cognitive development at school age. Pediatrics. 2014;133:412-421.

7. Grunau RE. Neonatal pain in very preterm infants: long-term effects on brain, neurodevelopment and pain reactivity. Rambam Maimonides Med J. 2013;4:e0025

8. Gao H, Gao H, Xu G, et al. Efficacy and safety of repeated oral sucrose for repeated procedural pain in neonates: a systematic review. Int J Nurs Stud. 2016;62:118-125.

9. SK Jatana, SS Dalal, CG Wilson. Analgesic effect of oral glucose in neonates. Med $J$ Armed Forces India. 2003;59:100-104, exists in practicing a neonatal analgesia, so we request clinical workers, hospital managers, and parents to pay more attention and promote the progress of neonatal pain management.

\section{Acknowledgment}

We would like to appreciate the work of editors and anonymous reviewers. The authors have declared that no competing interests exist. The study was not supported by any sources.

\section{Ethical approval}

Ethical issues are not involved in this paper.

\section{Conflicts of interest}

All contributing authors declare no conflicts of interest.
10. Gray L, Garza E, Zageris D, Heilman KJ, Porges SW. Sucrose and warmth for analgesia in healthy newborns: an RCT. Pediatrics. 2015;135:e607-e614.

11. Liaw JJ, Yang L, Katherine Wang KW, Chen CM, Chang YC, Yin T. Non-nutritive sucking and facilitated tucking relieve preterm infant pain during heel-stick procedures: a prospective, randomised controlled crossover trial. Int J Nurs Stud. 2012;49: 300-309.

12. Carbajal R, Chauvet $\mathrm{X}$, Couderc $\mathrm{S}$, Olivier-Martin $M$. Randomised trial of analgesic effects of sucrose, glucose, and pacifiers in term neonates. BMJ. 1999;319:1393-1397.

13. De Bernardo G, Riccitelli M, Sordino D, et al. Oral $24 \%$ sucrose associated with nonnutritive sucking for pain control in healthy term newborns receiving venipuncture beyond the first week of life. J Pain Res. 2019;12:299-305.

14. Gibbins S, Stevens B. Mechanisms of sucrose and non-nutritive sucking in procedural pain management in infants. Pain Res Manag. 2001;6:21-28.

15. Carbajal R, Veerapen $S$, Couderc $S$, Jugie $M$, Ville Y. Analgesic effect of breast feeding in term neonates: randomised controlled trial. BMJ. 2003;326:13-17.

16. Shah PS, Herbozo C, Aliwalas LL, Shah VS. Breastfeeding or breast milk for procedural pain in neonates. Cochrane Database Syst Rev. 2012;12:CD004950. 
17. Soltani S, Zohoori D, Adineh M. Comparison the effectiveness of breastfeeding, oral $25 \%$ dextrose, kangaroo-mother care method, and EMLA cream on pain score level following heal pick sampling in newborns: a randomized clinical trial. Electron Physician. 2018;10:6741-6748.

18. Hartley KA, Miller CS, Gephart SM. Facilitated tucking to reduce pain in neonates: Evidence for best practice. Adv Neonatal Care. 2015;15:201-208.

19. Kucukoglu S, Kurt S, Aytekin A. The effect of the facilitated tucking position in reducing vaccination-induced pain in newborns. Ital $J$ Pediatr. 2015;41:61.

20. Mellis C. Kangaroo mother care and neonatal outcomes: a meta-analysis. J Paediatr Child Health. 2016;52:579.

21. Johnston CC, Filion F, Campbell-Yeo M, et al. Kangaroo mother care diminishes pain from heel lance in very preterm neonates: a crossover trial. BMC Pediatr. 2008;8:13-21.

22. Kostandy RR, Ludington-Hoe SM, Cong $X$, et al. Kangaroo Care (skin contact) reduces crying response to pain in preterm neonates: pilot results. Pain Manag Nurs. 2008;9:55-65.

23. van Sleuwen BE, Engelberts AC, BoereBoonekamp MM, Kuis W, Schulpen TW, L'Hoir MP. Swaddling: a systematic review. Pediatrics. 2007;120:1097-1106.

24. Dezhdar S, Jahanpour F, Firouz Bakht S, Ostovar A. The effects of kangaroo mother care and swaddling on venipuncture pain in premature neonates: a randomized clinical trial. Iran Red Crescent Med J. 2016;21:e29649.

25. Cignacco E, Hamers JP, Stoffel L, et al. The efficacy of non-pharmacological interventions in the management of procedural pain in preterm and term neonates. A systematic literature review. Eur $J$ Pain. 2007;11:139-152.

26. Shu SH, Lee YL, Hayter M, Wang RH. Efficacy of swaddling and heel warming on pain response to heel stick in neonates: a randomised control trial. J Clin Nurs. 2014;23:3107-3114.

27. Bellieni CV, Cordelli DM, Marchi S, et al. Sensorial saturation for neonatal analgesia. Clin J Pain. 2007;23:219-221.

28. Harling L, Shaik MS, Tjosvold L, Leich R, Liang Y, Kumar M. Music for medical indications in the neonatal period: a systematic review of randomized controlled trials. Arch Dis Child Fetal Neonatal Ed. 2009;94:F349-F354.

29. Liu YY, Xie FF, Duan-Mu YY. Research on the application of music nursing for neonatal pain in NICU. J Qiqihar Med Univ. 2018;39:1104-1105 (in Chinese).
30. Azarmnejad E, Sarhangi F, Javadi M, Rejeh N. The effect of mother's voice on arterial blood sampling induced pain in neonates hospitalized in neonate Intensive Care Unit. Glob J Health Sci. 2015;7:198-204.

31. Uematsu H, Sobue I. Effect of music (Brahms lullaby) and non-nutritive sucking on heel lance in preterm infants: a randomized controlled crossover trial. Paediatr Child Health. 2019;24:e33-e39.

32. Qiu J, Jiang YF, Li F, Tong QH, Rong H, Cheng R. Effect of combined music and touch intervention on pain response and $\beta$-endorphin and cortisol concentrations in late preterm infants. BMC Pediatr. 2017;17:38.

33. Anand K.J.S, Bergqvist L, Hall RW, Carbajal R. Acute pain management in newborn infants. Pain Clinical Updates. 2011;19. https://s3.amazonaws.com/ rdcms-iasp/files/production/public/Content/ContentFolders/Publications2/PainClinicalUpdates/Archives/ PCU_19-6_final_12-8-11_1390260191290_1.pdf. Accessed December 27, 2019.

34. Wu SL, Yan J, Wen H, et al. Nursing Practice of pain management of Non - nutritive sucking combined with swaddling in newborn puncture. J Qiqihar Med Coll. 2015;30:4633-4634 (in Chinese).

35. Zhang JW, Zhang RD, Bai J, Chen L. Analgesic efficacy of glucose and pacifier in neonates during caudal blockage. J Clin Res. 2007;24:2097-2099 (in Chinese).

36. Zhou J, Fang JP, Chen HF, Jiang LY. Efficacy of oral sucrose solution in pain management of neonatal lumbar puncture. Chin Gen Pract. 2013;16:36003601 (in Chinese).

37. Lago P, Garetti E, Pirelli A, et al. Non-pharmacological intervention for neonatal pain control. Ital $J$ Pediatr. 2014;40(suppl 2):A52.

38. Pillai Riddell RR, Racine NM, Gennis HG, et al. Non-pharmacological management of infant and young child procedural pain. Cochrane Database Syst Rev. 2015;2015:CD006275.

39. Wang QL, Yao WY, Xu J, Cai XN. Study on cognitive of newborns' pain in medical staff of department of neonatal intensive care unit and influencing factors. Chin J Prac Nurs. 2017;33:446-450 (in Chinese).

40. Wang YJ, Sun J, Li W, Zheng XL, Wang NC, Li Y. The knowledge and attitudes regarding pain management for children among 113 pediatric nurses. Chin J Nurs. 2013;482:167-169 (in Chinese).

41. Pan LX, Shang F. Survey of effect of parents involving in pain management of neonate. Chin Nurs Res. 2014;28:198-199 (in Chinese).

42. Ye Q, Gong X, Liu Y. Investigation and analysis of cognition status of pain management of nurses in 
department of Neonatology. Nurs Practice Res. 2017;14:4-6 (in Chinese).

43. Zhong CX, Liao XM, Liu FLZ, et al. Evaluation of the training of neonatal pain management for nurses in the NICU. Nurs J Chin PLA. 2016;33:74-76 (in Chinese).

44. Gimenez IL, Arakaki VDSNM, Correa RM, et al. Neonatal pain: Characterization of the physiotherapist's perception in the neonatal intensive care unit Rev Paul Pediatr. 2019;38:e2018178.

45. Maciel HIA, Costa MF, Costa ACL, Marcatto JO, Manzo BF, Bueno M. Pharmacological and nonpharmacological measures of pain management and treatment among neonates. Rev Bras Ter Intensiva. 2019;31:21-26.

46. Bonutti DP, Daré MF, Castral TC, Leite AM, ViciMaia JA, Scochi CGS. Dimensioning of painful procedures and interventions for acute pain relief in premature infants. Rev Latino-Am Enfermagem. 2017;25:e2917.

47. Asadi-Noghabi F, Tavassoli-Farahi M, Yousefi $H$, Sadeghi T. Neonate pain management: what do nurses really know? Glob J Health Sci. 2014;6:284-293.

48. Kothari SY, Dongara AR, Nimbalkar SM, Phatak AG, Nimbalkar AS. Missed opportunities for sedation and pain management at a level iii neonatal Intensive Care Unit. India Front Pediatr. 2016;4:7

49. Ozawa M, Yokoo K, Funaba $Y$, et al. A quality improvement collaborative program for neonatal pain management in Japan. Adv Neonatal Care. 2017;17:184-191.

50. Harrison D, Zhou Y, McArthur L. Effectiveness of parents and clinicians working together to improve pain management in newborns. CMAJ. 2018;190(suppl):S26-S27. 